\title{
Pengaruh Temperatur Penyimpanan Terhadap Mutu dan Kualitas Minyak Goreng Kelapa Sawit
}

\author{
Fadly Husain $^{1}$, Ismail Marzuki ${ }^{2}$ \\ ${ }^{1,2}$ Program Studi Teknik Kimia, Universitas Fajar, Sulawesi Selatan, K.Pos 90231, Indonesia, (0411)447508 \\ *Korespondensi email: ismailmz@unifa.ac.id; ismailmz3773@gmail.com
}

Diterima: 4 Agustus 2021

Disetujui: 30 September 2021

\begin{abstract}
The MGKS storage temperature can cause changes in the percentage of free fatty acids (FFA), peroxide number (PV) and oil color so that the quality and quality of the oil decreases. This study aims to comprehensively analyze the factors related to the quality of palm cooking oil based on storage temperature parameters. Titration method is used to determine changes in FFA and PV values, while color determination uses a lovibond tintometer to analyze changes in these parameters based on changes in storage temperature in the range of $18{ }^{\circ} \mathrm{C}-36{ }^{\circ} \mathrm{C}$, treatment increases every $2{ }^{\circ} \mathrm{C}$. The average change in the FFA value for every $2{ }^{\circ} \mathrm{C}$ increase in the sample Sp.A $=0.1071 \%$; Sp.B $=0.1097 \%$; Sp.C $=0.1111 \%$. Changes in PV of Sp.A samples; Sp.B and Sp.C respectively $1.152 \mathrm{meq} / \mathrm{kg} ; 1.266 \mathrm{meq} / \mathrm{kg}$ and $1,352 \mathrm{meq} / \mathrm{kg}$, while the color changes that appear in the three samples are $2.34 ; 2.46$ and 2.67. These results show that every $2{ }^{\circ} \mathrm{C}$ increase in MGKS storage temperature affects the quality and quality of the oil. MGKS Sp.A is more stable than samples Sp.B and Sp.C. Changes in the FFA value of the three samples were stable in the temperature range $18{ }^{\circ} \mathrm{C}-36^{\circ} \mathrm{C}$. Changes in the FFA value of the three samples were stable in the temperature range of $18{ }^{\circ} \mathrm{C}$ $-36{ }^{\circ} \mathrm{C}$. Sp.A samples are more stable in maintaining PV values and color against changes and increases in storage temperature compared to Sp.B and Sp.C.
\end{abstract}

Keywords: storage temperature, palm oil quality, FFA, peroxide number, oil color

\begin{abstract}
Abstrak
Temperatur penyimpanan MGKS dapat menyebabkan perubahan nilai persen asam lemak bebas (FFA), bilangan peroksida (PV) dan warna minyak sehingga, mutu dan kualitas minyak menurun. Penelitian ini bertujuan untuk menganalisis secara komprehensif faktor-faktor yang berkaitan dengan mutu minyak goreng kelapa sawit berdasarkan parameter temperatur penyimpanan. Metode titrasi digunakan dalam menentukan perubahan nilai FFA dan PV, sedangkan penentuan warna menggunakan lovibond tintometer untuk menganalisis perubahan parameter tersebut berdasarkan perubahan suhu penyimpanan dalam range $180 \mathrm{C}-36{ }^{\circ} \mathrm{C}$, perlakuan kenaikan setiap $2{ }^{\circ} \mathrm{C}$. Rerata perubahan nilai FFA setiap kenaikan $20 \mathrm{C}$ sampel Sp.A $=0,1071 ;$ Sp.B = 0,1097; Sp.C = 0,1111. Perubahan PV sampel Sp.A; Sp.B dan Sp.C berturut-turut 1,$152 ; 1,266$ dan 1,352 , sedangkan perubahan warna yang tampak ketiga sampel berturut-turut 2,34; 2,46 dan 2,67. Hasil tersebut menunjukkan kenaikan setiap $2{ }^{\circ} \mathrm{C}$ temperatur penyimpanan MGKS berpengaruh terhadap mutu dan kualitas minyak. MGKS Sp.A lebih stabil dibandingkan sampel Sp.B dan Sp.C. Perubahan nilai FFA ketiga sampel stabil pada range temperatur $18{ }^{\circ} \mathrm{C}-36{ }^{\circ} \mathrm{C}$. Sampel Sp.A lebih stabil dalam mempertahankan nilai PV dan warna terhadap perubahan dan kenaikan temperatur penyimpanan dibandingkan Sp.B dan Sp.C.
\end{abstract}

Kata kunci: temperatur penyimpanan, kualitas minyak sawit, FFA, bilangan peroksida, warna minyak

\section{Pendahuluan}

Penyimpanan minyak goreng kelapa sawit (MGKS) dalam jangka waktu tertentu seringkali menjadi masalah yang dihadapi oleh para produsen besar. Karakteristik minyak sawit perlu diketahui dengan baik untuk melakukan penyimpanan agar tidak mengalami penurunan kualitas selama masa penyimpanan [1]. Penentuan temperatur penyimpanan yang ideal dalam waktu tertentu adalah sebuah masalah yang sulit diperkirakan, karena minyak sawit dominan tersusun atas lemak jenuh mencapai $\pm 50,12 \%$ dan lemak tak jenuh $\pm 49,20 \%$ dan sisanya adalah komponen anorganik $\pm 0,68 \%$ [2]. Komponen penyusun minyak sawit berupa lemak jenuh tinggi berwujud semi padat pada temperatur kamar, diantaranya asam palmitat $( \pm 43,75$ $\%)$, asam stearate $( \pm 5,11 \%)$, asam miristat $( \pm 1,4 \%)$ dan asam laurat $( \pm 0,12 \%)$ [3]. Minyak sawit juga mengandung beberapa jenis lemak tak jenuh, diantaranya asam oleat $( \pm 38,71 \%)$, asam linoleat $( \pm 10,14$ $\%)$, dan asam alfa linoleat $( \pm 0,35 \%)$ [4]. 
Kandungan lemak tak jenuh pada minyak sawit secara struktur molekul memiliki banyak ikatan rangkap karbon-karbon. Semakin banyak ikatan rangkap dalam minyak semakin reaktif terhadap oksigen dan kurang stabil pada perubahan suhu tertentu, sehingga relatif mudah mengalami reaksi oksidasi dengan adanya molekul air, sebaliknya komponen asam lemak jenuh pada minyak nabati rentan mengalami reaksi hidrolisis [5]. Potensi reaksi oksidasi dan reaksi hidrolisis dalam minyak memicu kualitas minyak mengalami penurunan. Kondisi tersebut di perpara dengan adanya potensi terjadi reaksi hidrogenasi, yaitu masuknya molekul hidrogen dalam struktur lemak untuk menjenuhkan ikatan rangkap, sehingga komponen lemak tak jenuh mengalami konversi menjadi lemak jenuh [6][7].

Faktor yang mempengaruhi kemurnian minyak goreng, khususnya MGKS adalah kandungan asam lemak bebas atau free fatty acid disingkat FFA [8]. Kadar komponen asam lemak bebas dalam minyak goreng dapat mengalami peningkatan jika terjadi reaksi oksidasi atau karena mengalami reaksi hidrolisis [9]. Reaksi ini ditandai dengan putusnya struktur ikatan rangkap karbon-karbon lemak tak jenuh dalam minyak atau dengan kata lain minyak goreng mengalami perubahan menuju ke struktur jenuh. Peristiwa ini dapat terjadi jika minyak mengalami peningkatan temperatur selama masa penyimpanan. Pada kondisi ini biasanya diikuti dengan terbentuknya warna pucat dalam minyak, sehingga dapat dikatakan bahwa minyak goreng mengalami penurunan mutu [10]. Minyak goreng berbahan primer kelapa sawit kualitas tinggi apabila mengandung komponen asam lemak bebas maksimum $2 \%$ saat pengolahan dan maksimum $5 \%$ minyak goreng dalam kemasan kualitas standar [1][11].

Faktor lain yang mempengaruhi mutu minyak goreng adalah kandungan kadar air, bilangan peroksida, kandungan asam lemak bebas, dan komponen pengotor dalam minyak. Perubahan kadar komponen FFA, bilangan peroksida, kadar air, warna dan kotoran dalam badan minyak goreng dapat disebabkan karena temperatur penyimpanan yang tidak pada nilai ideal, waktu simpan, terlalu lama, titik cair, refining loss, kandungan gliserida, plastisitas, kejernihan, spreadability, bilangan peroksida dan kandungan logam berat [12]. Faktor-faktor tersebut perlu dianalisis untuk menentukan kondisi ideal minyak goreng, sehingga kualitas minyak tersebut dapat dipertahankan selama masa penyimpanan [13].

Minyak kelapa sawit (Crude Palm Oil) disingkat CPO merupakan minyak nabati yang diperoleh dengan metode ekstraksi dari buah kelapa sawit. Jenis kelapa sawit yang banyak dibudidayakan untuk produksi CPO umumnya berasal dari spesies Elaeis guineensis dan sedikit dari spesies Attalea maripa dan Elaeis oleifera [13]. Kondisi alamiah, minyak kelapa sawit tampak berwarna merah merah, disebabkan karena komponen beta-karoten yang tinggi dari minyak tersebut. Minyak yang berbahan dasar buah kelapa sawit terdiri atas dua jenis, yakni minyak inti sawit (palm kernel oil), dihasilkan dari inti buah sawit dan minyak sawit yang dihasilkan dari kelapa sawit [2]. Ciri khas minyak inti sawit adalah tidak tampak berwarna merah karena kandungan karotenoidnya sangat sedikit, demikian pula kandungan kadar lemak jenuh dalam konsentrasi rendah [14].

Beberapa reaksi kimia yang dapat terjadi pada minyak atau lemak, diantaranya: (1) Reaksi hidrolisis, yaitu masuknya molekul air dalam badan minyak. Molekul air pecah menjadi kation hidrogen dan anion hidroksida membentuk reaksi asam-basa seimbang dengan komponen lemak, sehingga ikatan oksigenkarbon karbonil putus dan terjadi konversi minyak menjadi gliserol dan asam lemak bebas. Jika terjadi reaksi hidrolisis dalam badan minyak dapat memicu penurunan mutu minyak (rusak), karena terdapat sejumlah molekul air dalam struktur minyak; (2) Reaksi oksidasi lemak dapat terjadi melalui mekanisme autooksidasi, fotooksidasi, dan oksidasi enzimatik yang secara prinsip terjadi proses perubahan struktur ikatan karena adanya interaksi antara molekul gas oksigen $\left(\mathrm{O}_{2}\right)$ di sekitar ikatan ganda dua (tidak jenuh) molekul gliserida penyusun minyak atau lemak. Akibat reaksi oksidasi mengakibatkan bau tengik pada minyak dan lemak; (3) Reaksi hidrogenasi terjadi jika terdapat molekul $\mathrm{H}_{2}$ masuk ke dalam struktur ikatan rangkap dua karbon radikal atau molekul gliserida, menyebabkan lemak mengalami peningkatan sifat kejenuhan; (4) Reaksi esterifikasi merupakan proses konversi asam lemak penyusun trigliserida menjadi metil ester, sehingga komponen FFA semakin berkurang, sehingga potensi aroma tidak enak dari asam lemak rantai pendek dapat diubah menjadi rantai panjang bersifat tidak menguap [3] [15].

Komposisi komponen asam lemak jenuh dan tak jenuh penyusun CPO relatif berimbang. Asam lemak jenuh termasuk gliserol merupakan komponen utama minyak nabati. Asam lemak dalam CPO sebagian besar merupakan asam lemak jenuh jenis asam palmitat, sehingga minyak CPO tampak lebih stabil atau kurang reaktif oleh pengaruh internal dan eksternal minyak dibandingkan dengan jenis minyak lainnya [13]. Namun demikian, CPO tetap rentan mengalami perubahan komposisi komponen penyusun disebabkan karena dalam CPO juga mengandung komponen tak jenuh. Ikatan rangkap dua komponen asam lemak tak jenuh dalam CPO terdiri atas dua jenis yakni struktur "trans" relatif lebih stabil dan struktur "cis" yang kurang stabil, menyebabkan minyak tersebut reaktif dan mudah bereaksi dengan oksigen udara (mudah teroksidasi) [4][16]. 
Komponen asam lemak bebas (FFA) dalam minyak merupakan ukuran mutu dan kualitas minyak. Persen FFA dinyatakan dengan bilangan asam atau angka asam. Kualitas minyak dapat ditentukan dengan melakukan beberapa macam pengujian yang didasarkan pada beberapa penetapan komponen kimia minyak atau lemak, diantaranya: penetapan persen FFA, bilangan peroksida, bilangan iod, bilangan penyabunan atau melalui uji fisika seperti penentuan bobot jenis, indeks bias, titik cair, dan kadar air minyak atau lemak [17]. Pengujian bilangan peroksida dimaksudkan untuk mengetahui dan menentukan indeks jumlah minyak atau lemak yang telah mengalami perubahan struktur melalui proses oksidasi [18]. Semakin tinggi bilangan peroksida yang dicapai menunjukkan semakin banyak reaksi oksidasi yang terjadi dalam minyak atau lemak khususnya pada asam lemak tidak jenuh menghasilkan senyawa peroksida akibat teroksidasi oleh molekul oksigen, dengan demikian potensi timbulnya bau tengik pada minyak semakin tinggi atau kualitas minyak semakin rendah [19]. Beberapa data ilmiah menunjukkan bahwa persenyawaan peroksida tidak stabil terhadap perubahan panas. Panas yang mencapai $200{ }^{\circ} \mathrm{C}$ menyebabkan kenaikan kekentalan dan indeks bias, karena pada suhu tersebut jumlah senyawa polimer yang terbentuk relatif besar [20].

Pengujian warna minyak dilakukan untuk mengetahui warna. Warna minyak goreng sangat berpengaruh pada mutu dan kualitas CPO. Pengujian colour dilakukan menggunakan alat lovibond tintometer. Warna CPO terdiri atas 2 kategori, yaitu: pertama, warna alamiah adalah warna alamiah dari minyak yang ikut terekstraksi bersama minyak [21]. Zat warna alami ini antara lain kandungan $\alpha$ dan $\beta$ karoten memberi warna kuning, zat xantofil memberi kuning kecoklatan, klorofil warna kehijauan, dan zat antosianin menyumbang berwarna kemerahan; kedua, zat warna hasil degradasi warna alamiah diperkirakan terjadi selama masa pengolahan dan penyimpanan [22]. Zat warna minyak kecoklatan hasil degradasi terjadi karena adanya reaksi oksidasi terhadap komponen tokoferol (zat vitamin E) yang kemungkinan disebabkan karena bahan baku pembuatan minyak berupa buah kelapa sawit sudah busuk dan rusak [23].

Minyak sawit mempunyai banyak keunggulan sebagai bahan utama dan pemakaian luas produk pangan. Keunggulan minyak sawit, diantaranya: (1) harga yang relatif murah; (2) mudah diperoleh dengan tingkat populasi sangat besar, (3) mengandung zat antioksidan alami dan dapat berfungsi sebagai pengawet alami; (4) membuat bahan makanan bertekstur lembut dan halus; (5) bebas dari lemak trans; (5) tidak berbau dan tidak berasa; dan (7) meningkatkan cita rasa pada bahan makanan [11][12]. Tujuan penelitian ini adalah melakukan analisis dengan komprehensif beberapa faktor yang berkaitan dengan mutu dan kualitas minyak sawit berdasarkan parameter temperatur penyimpanan.

\section{Metode Penelitian \\ Tempat dan Waktu Penelitian}

Penelitian tentang pengaruh temperatur penyimpanan terhadap mutu dan kualitas minyak goreng kelapa sawit terhadap mutu dan kualitas minyak sawit berdasarkan parameter temperatur penyimpanan dilaksanakan di laboratorium kimia terpadu Program studi Teknik Kimia Universitas Fajar, sedangkan pengukuran dilaksanakan di Balai Industri Regional Makassar. Penelitian dilaksanakan selama 2 bulan, terhitung 17 Maret sampai 29 April 2021.

\section{Alat dan Bahan}

Alat yang digunakan pada pengujian ini antara lain, yaitu neraca analitik, seperangkat alat titrasi, pipet tetes, pipet $1 \mathrm{ml}$, gelas beker pyrex, buret, Erlenmeyer, spatula kaca, pipet volume $10 \mathrm{ml}$, corong pemisah $500 \mathrm{ml}$, hot plate stirrer, centrifugal, thermometer Polygreen, lovibond tintometer, bola hisap, seperangkat alat pendingin, kertas saring, dan desikator.

Bahan yang digunakan antara lain, yaitu minyak goreng dari kelapa sawit, $\mathrm{CH}_{2} \mathrm{COOH}$, kloroform, KI Jenuh, $\mathrm{NaOH} 0,0983 \mathrm{~N}$ dan $\mathrm{Na}_{2} \mathrm{~S}_{2} \mathrm{O}_{3} 0,1011 \mathrm{~N}$ (hasil standarisasi), amilum $1 \%$, aquades, $\mathrm{HCl} 0.5 \mathrm{~N}$, Alkohol absolut, dan fenolftalein (PP) dan alkohol netral.alat yang digunakan pada pengujian ini antara lain: neraca analitik, seperangkat alat titrasi, pipet tetes, pipet $1 \mathrm{ml}$, gelas beker pyrex, buret, Erlenmeyer, spatula kaca, pipet volume $10 \mathrm{ml}$, corong pemisah $500 \mathrm{ml}$, hot plate stirrer, centrifugal, thermometer Polygreen, lovibond tintometer, bola hisap, seperangkat alat pendingin, kertas saring, dan desikator.

\section{Prosedur Penelitian}

Pengujian persen FFA dilakukan dengan prosedur: menimbang $\pm 16 \mathrm{~g}$ sampel dalam erlenmeyer. Sebanyak $10 \mathrm{~mL}$ alkohol netral dipanaskan menggunakan hot plate. Alkohol netral panas di campur ke dalam sampel yang telah ditimbang dan tambahkan $1 \mathrm{~mL}$ indikator PP. Titrasi dengan larutan $\mathrm{NaOH} \mathrm{0,0983}$ $\mathrm{N}$ hingga terbentuk warna merah jambu dan tidak hilang selama 30 detik. Volume $\mathrm{NaOH}$ yang digunakan dicatat. Menghitung kadar asam lemak bebas dinyatakan sebagai \% FFA dalam angka [2].

Penentuan bilangan peroksida mengikuti prosedur: sampel $\pm 5 \mathrm{~g}$ dimasukkan ke dalam Erlenmeyer, ditambahkan $30 \mathrm{~mL}$ larutan $\mathrm{CH}_{2} \mathrm{COOH}$ : kloroform rasio 3:2, lalu di tutup rapat. Campuran diaduk hingga semua sampel larut. Larutan KI jenuh sebanyak 0,5 mL ditambahkan menggunakan pipet tetes, lalu ditutup 
kembali. Larutan didiamkan selama \pm 60 detik, diaduk kembali sampai pengadukan mencapai 3 kali setiap selang waktu 60 detik. Lalu ditambahkan aquades $\pm 30 \mathrm{~mL}$. Sampel ini, selanjutnya ditambah 1-2 tetes amilum $1 \%$, selanjutnya dititrasi dengan larutan $\mathrm{Na}_{2} \mathrm{~S}_{2} \mathrm{O}_{3} 0,1011 \mathrm{~N}$ tetes demi tetes sampai warna biru pada larutan bilang atau terbentuk warna putih [2][16].

Menentukan warna minyak dengan variasi temperatur penyimpanan dapat dilakukan dengan menggunakan lovibond tintometer model $\mathrm{F}$ dengan prosedur sambungkan alat dengan sumber arus listrik, memasukkan sampel minyak ke dalam kuvet (lovibond cell) sampai hampir penuh kira-kira 7/8 dari tinggi kuvet. Selanjutnya kuvet berisi sampel dimasukkan ke dalam alat tintometer pada posisi disesuaikan jarak, lalu tekan tombol power di posisi on. Warna dapat diamati pada lensa dan disesuaikan dengan rasio yang sudah ditentukan [17][24].

Analisis Data

Kadar asam lemak bebas ditentukan dengan menggunakan persamaan (1). Titrasi dilakukan menggunakan buret kaca, sehingga analisa harus mempertimbangkan nilai estimasi dan potensi ketidakpastian dari analisa yang telah dilakukan dengan mereview kesesuaian tahapan-tahapan yang telah dilakukan.

$$
\% F F A=\frac{25,6 \times N \mathrm{NaOH} \times \mathrm{Vtitran}}{W}
$$

Penentuan bilangan peroksida dengan menggunakan persamaan (2), sedangkan untuk menentukan nilai perubahan warna berdasarkan perubahan kenaikan $2{ }^{\circ} \mathrm{C}$ temperatur penyimpanan dapat langsung diketahui menggunakan lovibond tintometer.

$$
\text { Bil.perok. }(P V)=\frac{(\text { v.titran-v.blanko } \times N \text { tio } \times 1000}{W}
$$

\section{Hasil dan Pembahasan}

\section{Parameter Penilaian Mutu Minyak Goreng Kelapa Sawit}

Pengendalian dan pengawasan kualitas minyak goreng penting dilakukan, khususnya pada masa penyimpanan, karena sering kali terjadi perubahan-perubahan fisik dan kimia minyak selama masa penyimpanan. Variabel yang sangat penting dikendalikan adalah besaran temperatur ideal yang dapat disetting, sehingga variabel lainnya seperti nilai FFA, bilangan peroksida dan warna minyak tidak mengalami perubahan, atau minyak dalam kondisi dapat mempertahankan mutu dan kualitas MGKS selama masa penyimpanan [15][25]. Jalur dan mekanisme pemantauan hasil uji olein minyak dilakukan oleh petugas kualiti kontrol laboratorium untuk beberapa variabel yang dipersyaratkan, misalnya persen FFA, bilangan peroksida dan warna. Hasil uji diteruskan ke bagian Fractionation Plant untuk dicatat data standar mutu. Pencatatan data dijadikan kontrol untuk pengendalian mutu olein, sehingga apabila terdapat data yang dicatat mengalami perubahan dalam periode tertentu untuk segera dilakukan langkah pengendalian agar mutu dan kualitas minyak dapat dipertahankan [4] [26]. Beberapa data yang ditunjukkan dalam Tabel 1, berturut-turut merupakan hasil pengujian untuk tiga variabel MGKS, yakni: nilai perubahan persen asam lemak bebas (FFA), perubahan bilangan peroksida (PV) dan nilai perubahan warna berdasarkan temperatur penyimpanan [24].

Berdasarkan analisis dan olah data hasil pengukuran pada uji FFA menggunakan persamaan (1) ditunjukkan dalam Tabel 1 kolom 6, di atas. Merujuk pada standar nasional Indonesia tentang kualitas dan mutu minyak goreng kelapa sawit SNI 01-2901 Tahun 2002, menunjukkan bahwa ketiga jenis sampel minyak goreng kelapa sawit berturut-turut Sp.A; Sp.B dan Sp.C yang di lakukan pengendalian mutu dengan variasi temperatur penyimpanan $18{ }^{\circ} \mathrm{C}-36{ }^{\circ} \mathrm{C}$ perlakuan range peningkatan temperatur $2{ }^{\circ} \mathrm{C}$, persentase perubahan nilai FFA masih dalam kategori terkendali [18][27]. Makna terkendali yang dimaksud adalah nilai persen FFA minyak goreng uji dalam range yang dapat ditoleransi dan diperbolehkan sesuai dengan SNI maks. 5\%. Meskipun demikian dalam prakteknya, umumnya dilakukan setting temperatur penyimpanan MGKS yang dipilih oleh manajemen perusahaan adalah pada nilai temperatur sama dengan temperatur kamar, dimaksudkan untuk meminimalisasi penggunaan energi dalam rangka pengendalian suhu penyimpanan dan pertimbangan variabel lainnya yang relatif dapat dipertahankan berkaitan dengan mutu dan kualitas minyak goreng, misalnya bilangan peroksida, warna [20] [22].

Variabel pengendalian lainnya yang diuji hubungannya dengan temperatur penyimpanan MGKS adalah perubahan bilangan peroksida. Tabel 1 kolom 10, memperlihatkan hasil analisis data menggunakan persamaan (2), diperoleh nilai perubahan bilangan peroksida. Sesuai Tabel 1 kolom 10, dengan merujuk pada mutu dan kualitas minyak goreng menurut SNI 01-3741 Tahun 2013, khususnya variabel nilai 
bilangan peroksida, menunjukkan bahwa sampel Sp.A dapat disimpan dalam tangki maksimal pada suhu $28{ }^{\circ} \mathrm{C}$, sedangkan sampel Sp.B dan Sp.C hanya dapat disimpan pada temperatur maksimal $26{ }^{\circ} \mathrm{C}$, agar mutu dan kualitas minyak goreng kelapa sawit dapat dipertahankan pada nilai yang dapat ditoleransi sesuai dengan rekomendasi yang termuat dalam SNI 01-3741 [1].

Tabel 1. Parameter penilaian minyak goreng kelapa sawit (MGKS) berdasarkan Temperatur Penyimpanan dalam tangki

\begin{tabular}{|c|c|c|c|c|c|c|c|c|c|c|}
\hline \multirow[b]{2}{*}{$\begin{array}{c}\text { Jenis } \\
\text { Sampel }\end{array}$} & \multirow[b]{2}{*}{$\begin{array}{c}\text { Temp. } \\
\left({ }^{0} \mathrm{C}\right)\end{array}$} & \multicolumn{4}{|c|}{ Nilai Asam lemak bebas (FFA) } & \multicolumn{4}{|c|}{ Nilai Bilangan Peroksida (PV) } & \multirow[b]{2}{*}{$\begin{array}{l}\mathrm{LR} \\
(\mathrm{C})\end{array}$} \\
\hline & & $\mathrm{W}(\mathrm{g})$ & $\begin{array}{c}\mathrm{V} \\
(\mathrm{ml})\end{array}$ & $\begin{array}{c}\mathrm{N} . \\
\mathrm{NaOH}\end{array}$ & $\begin{array}{c}\text { FFA } \\
(\%)\end{array}$ & $\mathrm{W}(\mathrm{g})$ & $\mathrm{V}(\mathrm{ml})$ & $\begin{array}{c}\mathrm{N} \\
\mathrm{Na}_{2} \mathrm{~S}_{2} \mathrm{O}_{3}\end{array}$ & $\begin{array}{c}\mathrm{PV} \\
(\mathrm{meq} / \mathrm{kg})\end{array}$ & \\
\hline 1 & 2 & 3 & 4 & 5 & 6 & 7 & 8 & 9 & 10 & 11 \\
\hline Sp.A & & 16,9147 & 0,42 & 0,0983 & 0,062 & 5,5520 & 4,730 & 0,1011 & 0,67 & 1,80 \\
\hline Sp.B & 18 & 16,9745 & 0,46 & 0,0983 & 0,068 & 5,7260 & 5,825 & 0,1011 & 0,80 & 2,00 \\
\hline Sp.C & & 16,8142 & 0,47 & 0,0983 & 0,071 & 5,6012 & 6,125 & 0,1011 & 0,86 & 2,30 \\
\hline Sp.A & & 17,2846 & 0,56 & 0,0983 & 0,081 & 5,3652 & 4,776 & 0,1011 & 0,70 & 2,00 \\
\hline Sp.B & 20 & 17,4812 & 0,58 & 0,0983 & 0,083 & 5,4327 & 5,872 & 0,1011 & 0,85 & 2,10 \\
\hline Sp.C & & 17,6356 & 0,60 & 0,0983 & 0,085 & 5,3981 & 6,041 & 0,1011 & 0,88 & 2,40 \\
\hline Sp.A & & 20,4360 & 0,74 & 0,0983 & 0,091 & 5,4264 & 5,520 & 0,1011 & 0,80 & 2,20 \\
\hline Sp.B & 22 & 20,3604 & 0,75 & 0,0983 & 0,093 & 5,5324 & 6,121 & 0,1011 & 0,87 & 2,30 \\
\hline Sp.C & & 20,5573 & 0,75 & 0,0983 & 0,092 & 5,3256 & 6,027 & 0,1011 & 0,89 & 2,50 \\
\hline Sp.A & & 21,2250 & 0,78 & 0,0983 & 0,093 & 5,1762 & 5,661 & 0,1011 & 0,86 & 2,30 \\
\hline Sp.B & 24 & 21,3478 & 0,81 & 0,0983 & 0,096 & 5,2137 & 5,834 & 0,1011 & 0,88 & 2,30 \\
\hline Sp.C & & 21,4521 & 0,84 & 0,0983 & 0,098 & 5,2464 & 6,004 & 0,1011 & 0,90 & 2,50 \\
\hline Sp.A & & 22,6892 & 1,00 & 0,0983 & 0,111 & 5,3478 & 6,392 & 0,1011 & 0,94 & 2,40 \\
\hline Sp.B & 26 & 22,1968 & 1,01 & 0,0983 & 0,114 & 5,4327 & 7,737 & 0,1011 & 1,12 & 2,50 \\
\hline Sp.C & & 22,3860 & 1,04 & 0,0983 & 0,117 & 5,3981 & 8,374 & 0,1011 & 1,22 & 2,60 \\
\hline Sp.A & & 23,2349 & 1,13 & 0,0983 & 0,122 & 5,3465 & 7,479 & 0,1011 & 1,10 & 2,50 \\
\hline Sp.B & 28 & 23,7329 & 1,18 & 0,0983 & 0,125 & 5,4532 & 8,945 & 0,1011 & 1,29 & 2,60 \\
\hline Sp.C & & 23,9832 & 1,21 & 0,0983 & 0,127 & 5,4239 & 9,380 & 0,1011 & 1,36 & 2,70 \\
\hline Sp.A & & 24,9731 & 1,23 & 0,0983 & 0,124 & 5,6513 & 9,342 & 0,1011 & 1,30 & 2,50 \\
\hline Sp.B & 30 & 24,8329 & 1,24 & 0,0983 & 0,126 & 5,7346 & 9,772 & 0,1011 & 1,34 & 2,60 \\
\hline Sp.C & & 24,6782 & 1,26 & 0,0983 & 0,128 & 5,5998 & 10,396 & 0,1011 & 1,46 & 2,70 \\
\hline Sp.A & & 25,2579 & 1,27 & 0,0983 & 0,127 & 5,3579 & 10,220 & 0,1011 & 1,50 & 2,50 \\
\hline Sp.B & 32 & 25,6373 & 1,30 & 0,0983 & 0,128 & 5,4237 & 10,483 & 0,1011 & 1,52 & 2,70 \\
\hline Sp.C & & 25,4525 & 1,30 & 0,0983 & 0,129 & 5,5112 & 11,003 & 0,1011 & 1,57 & 2,80 \\
\hline Sp.A & & 26,4982 & 1,36 & 0,0983 & 0,129 & 5,4572 & 12,213 & 0,1011 & 1,76 & 2,60 \\
\hline Sp.B & 34 & 26,6347 & 1,39 & 0,0983 & 0,131 & 5,5612 & 13,224 & 0,1011 & 1,87 & 2,70 \\
\hline Sp.C & & 26,7523 & 1,40 & 0,0983 & 0,132 & 5,4873 & 14,514 & 0,1011 & 2,08 & 2,80 \\
\hline Sp.A & & 27,3478 & 1,42 & 0,0983 & 0,131 & 5,5631 & 13,370 & 0,1011 & 1,89 & 2,60 \\
\hline Sp.B & 36 & 27,4175 & 1,45 & 0,0983 & 0,133 & 5,5924 & 15,076 & 0,1011 & 2,12 & 2,80 \\
\hline Sp.C & & 27,6512 & 1,45 & 0,0983 & 0,132 & 5,6213 & 16,441 & 0,1011 & 2,30 & 2,90 \\
\hline
\end{tabular}

Adanya perbedaan batas toleransi suhu penyimpanan dari hasil uji ketiga jenis sampel tersebut dapat disebabkan karena beberapa faktor, diantaranya (1) faktor mutu dan kualitas sampel, dimana dapat disebabkan oleh ketidak seragaman buah kelapa sawit yang diolah, tingkat kematangan yang tidak seragam, masalah penyortiran bahan baku, termasuk waktu jedah setelah pemetikan buah untuk selanjutnya diangkut ke unit pengolahan (pabrik); (2) faktor pengolahan menjadi produk minyak kelapa sawit karena menggunakan mesin yang berbeda atau mesin sama namun terdapat hambatan selama pengolahan, karena ada bagian mesin yang rusak, penggantian alat dan masalah lainnya, berakibat pada waktu pengolahan; (3) masalah human error komponen SDM yang terlibat pengujian, baik pada saat pengujian bahan baku maupun pada saat uji kualitas produk [11].

Masalah-masalah tersebut di atas berpotensi menghasilkan produk minyak goreng dengan mutu dan kualitas tidak seragam. Membandingkan ketiga sampel tersebut untuk variabel bilangan peroksida hubungannya dengan temperatur penyimpanan dapat dikatakan bahwa sampel Sp.A lebih stabil pada suhu maksimal $28{ }^{\circ} \mathrm{C}$, sedangkan sampel Sp.B dan Sp.C diperkirakan tidak stabil pada suhu penyimpanan tersebut. Artinya bahwa SP.A masih dapat mempertahankan mutu dan kualitas khususnya nilai PV, dibandingkan Sp.B dan Sp.C pada suhu penyimpanan maksimum $26{ }^{\circ} \mathrm{C}$. 


\section{Perubahan Asam Lemak Bebas (FFA) Minyak Goreng Kelapa Sawit}

Variabel perubahan warna berdasarkan besaran temperatur penyimpanan juga menentukan kestabilan dan kualitas minyak goreng. Warna minyak goreng yang berkualitas dan memiliki mutu yang baik adalah warna putih-jernih, disusul warna kuning dan batas maksimum toleransi warna hingga kuning pucat [21]. Analisis perubahan warna minyak goreng kelapa sawit berdasarkan perubahan temperatur penyimpanan disajikan dalam Tabel 1, kolom 11.

Merujuk pada Tabel 1, kolom 11, di atas dan komparasi dengan standar mutu minyak goreng SNI 01-3741 revisi tahun 2002, menunjukkan bahwa mutu dan kualitas sampel Sp.A paling baik pada batas suhu penyimpanan $28{ }^{\circ} \mathrm{C}$, sedangkan Sp.B dan Sp.C di suhu $26{ }^{\circ} \mathrm{C}$. Analisis lebih dalam sesuai data Tabel 3, menunjukkan bahwa sampel minyak goreng kode Sp.A masih stabil pada suhu penyimpanan maksimum $28{ }^{\circ} \mathrm{C}$, namun untuk sampel Sp.B dan Sp.C stabil pada suhu penyimpanan lebih rendah $2{ }^{\circ} \mathrm{C}$ atau pada temperatur penyimpanan $26{ }^{\circ} \mathrm{C}$. Analisis lebih detail berkaitan dengan mutu dan kualitas minyak goreng tiga sampel uji (Sp.A; Sp.B; Sp.C) khususnya variabel persentase asam lemak bebas (FFA), bilangan peroksida (PV) dan warna berdasarkan temperatur penyimpanan, disajikan pada Gambar 1, Gambar 2, dan Gambar 3.

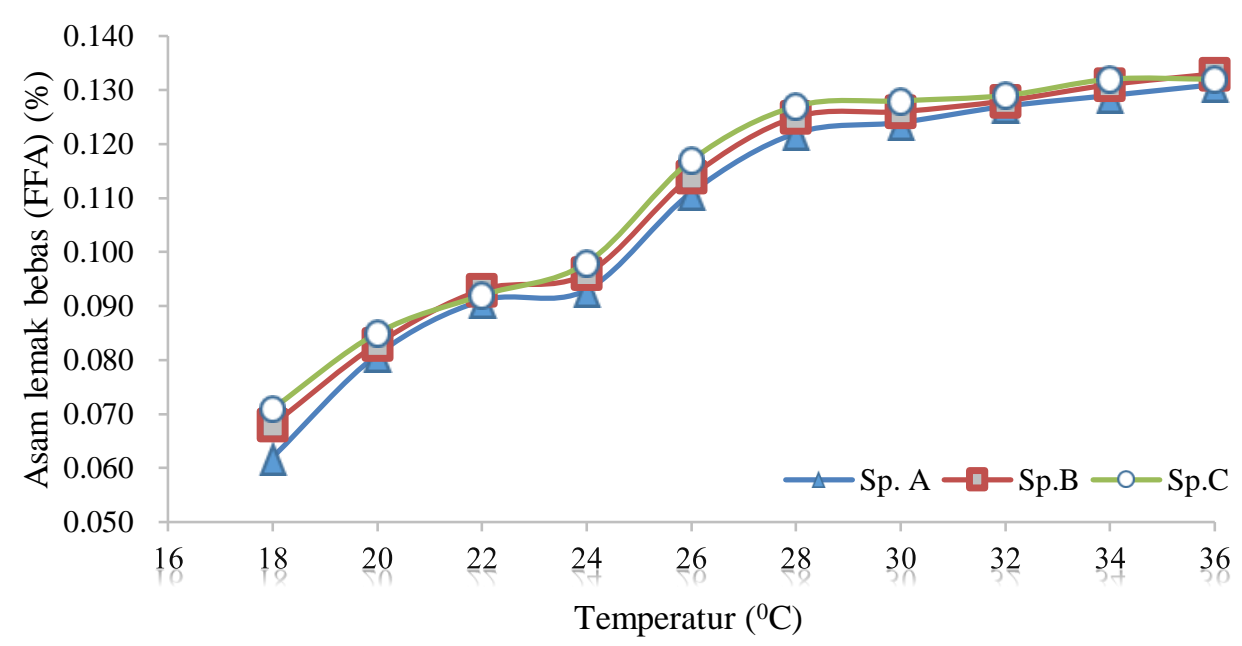

Gambar 1. Pengaruh temperature terhadap perubahan nilai asam lemak bebas (FFA) crude palm oil Sumber: Data Primer, 2021

Tampilan Gambar 1, menunjukkan bahwa sampel Sp.A memiliki kecenderungan lebih stabil terhadap persen perubahan asam lemak bebas (FFA) pada kenaikan temperatur penyimpanan setiap $2{ }^{\circ} \mathrm{C}$ dibandingkan Sp.B dan Sp.C. Hal ini dapat dilihat pada posisi sampel Sp.A paling bawah (Gambar 1), meskipun bentuk grafik ketiga sampel tersebut relatif sama. Sampel Sp.A lebih mampu mempertahankan nilai perubahan persen FFA terhadap kenaikan temperatur penyimpanan minyak goreng. Hal ini dikuatkan dengan rerata persen kenaikan nilai FFA sampel Sp.A; Sp.B dan Sp.C berturut-turut 0,1071 \%; 0,1097\% dan $0,1111 \%$, meskipun persen perubahan FFA ketiga sampel MGKS ini masih dalam batas toleransi sesuai dengan persyaratan standar SNI.

\section{Perubahan Bilangan Peroksida Minyak Goreng Kelapa Sawit}

Analisis terhadap ketiga sampel minyak goreng terkait dengan variabel bilangan peroksida berdasarkan temperatur penyimpanan, memberi gambaran yang menunjukkan bahwa ada pengaruh temperatur penyimpanan terhadap bilangan peroksida MGKS. Pengaruih tersebut berdasarkan tampilan Gambar 2, menunjukkan bahwa sampel Sp.A lebih stabil dibandingkan Sp.B dan Sp.C dalam mempertahankan nilai bilangan peroksida terhadap setiap kenaikan temperatur penyimpanan sebesar $2{ }^{\circ} \mathrm{C}$. 


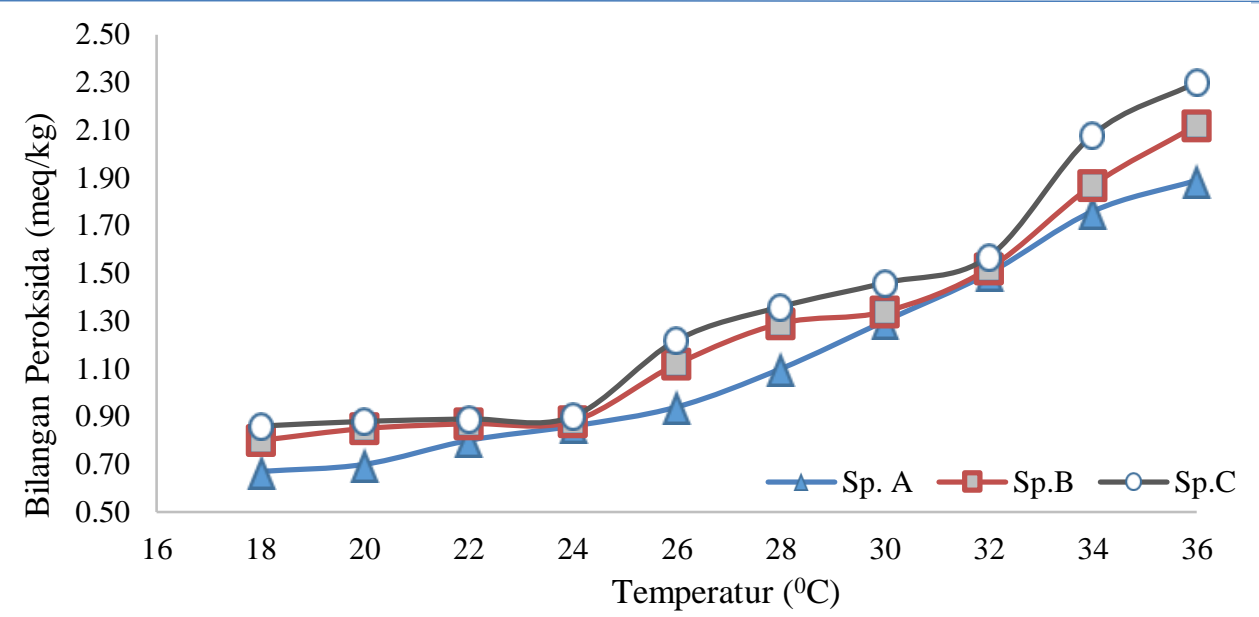

Gambar 2. Pengaruh temperatur terhadap perubahan nilai bilangan peroksida (PV) crude palm oil Sumber: Data primer, 2021

Hal ini didasarkan pada tiga keadaan, yakni: pertama, posisi paling bawah sampel Sp.A dalam grafik (Gambar 2); kedua, bentuk perubahan grafik Sp.A lebih teratur dibandingkan bentuk grafik sampel Sp.B dan Sp.C yang relatif kurang teratur. Bentuk grafik teratur atas perubahan suhu penyimpanan memberi makna bahwa sampel minyak goreng lebih stabil dalam mempertahankan nilai perubahan bilangan peroksidanya, sebaliknya grafik tidak teratur menunjukkan bahwa sampel kurang mampu mempertahankan perubahan bilangan peroksidanya akibat perubahan temperatur penyimpanan; dan ketiga, rerata perubahan nilai PV setiap kenaikan temperatur penyimpanan $2{ }^{\circ} \mathrm{C}$ sampel Sp.A; Sp.B dan Sp.C berturut-turut 1,152 $\mathrm{meq} / \mathrm{kg} ; 1,266 \mathrm{meq} / \mathrm{kg}$ dan $1,352 \mathrm{meq} / \mathrm{kg}$. Kenaikan nilai PV setiap kenaikan $2{ }^{\circ} \mathrm{C}$ suhu penyimpanan MGKS memiliki pengaruh lebih kecil, dengan kata lain Sp.A lebih stabil dibandingkan Sp.B dan Sp.C.

Perubahan Tampilan Warna Minyak Goreng Kelapa Sawit

Warna minyak goreng, khususnya minyak kelapa sawit berkaitan dengan kandungan senyawasenyawa organik dalam minyak. Umumnya senyawa organik dalam minyak mudah menguap karena memiliki titik didih yang relatif rendah, sehingga jika terjadi perubahan temparatur, waktu penyimpanan, memberi pengaruh pada perubahan warna minyak tersebut. Perubahan warna minyak sangat berfluktuasi karena pengaruh senyawa organik minyak sebagai zat gizi yang umumnya volatil.

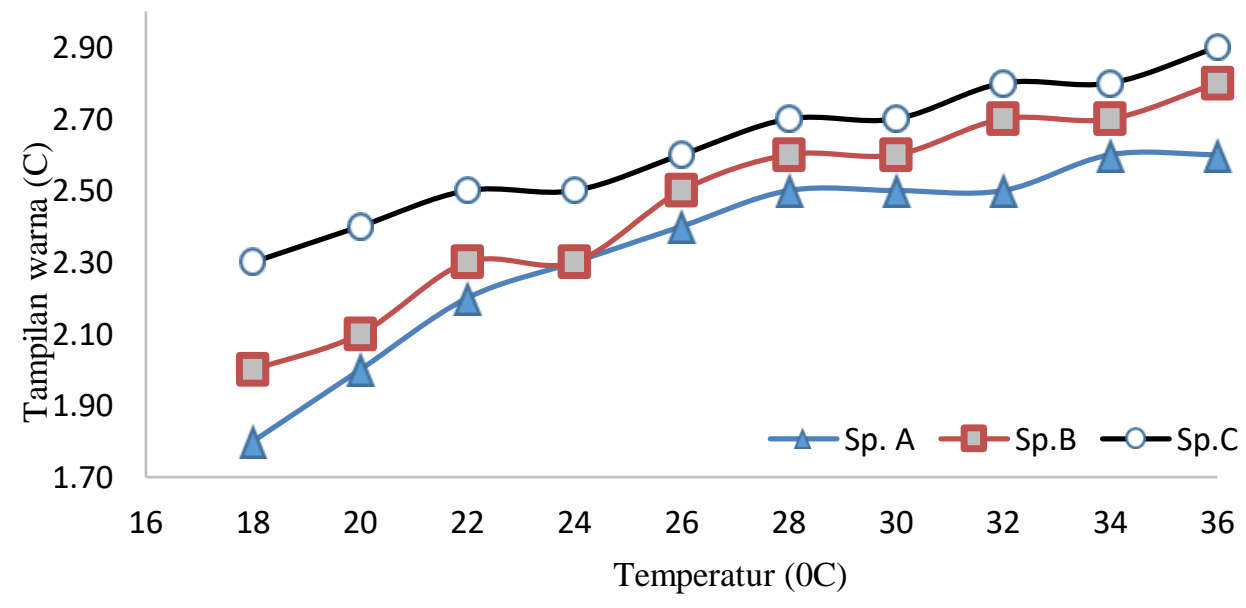

Gambar 3. Pengaruh temperature terhadap perubahan warna crude palm oil Sumber: Data primer, 2021

Fluktuasi perubahan nilai warna minyak goreng atas perubahan temperatur penyimpanan, menunjukkan bahwa ada respon minyak goreng tersebut atas kenaikan suhu penyimpanan sebesar $2{ }^{\circ} \mathrm{C}$. Tampak pada Gambar 3, menguatkan persepsi bahwa sampel minyak goreng Sp.A lebih stabil dalam mempertahankan warna atas perubahan suhu penyimpanan. Bentuk grafik sampel SP.A (Gambar 3) tampak lebih teratur dibandingkan grafik sampel Sp.B dan Sp.C, artinya Sp.A lebih toleran terhadap kenaikan temperatur penyimpanan setiap $2{ }^{\circ} \mathrm{C}$ dalam mempertahankan perubahan warna. Hal ini dapat dikuatkan dengan menganalisis rerata perubahan warna minyak sampel SP.A sebesar 2,34, lebih rendah 
dibandingkan perubahan warna sampel Sp.B $=2,46$, dan $\mathrm{Sp} . \mathrm{C}=2,67$. Artinya pengaruh kenaikan $2{ }^{\circ} \mathrm{C}$ suhu penyimpanan dalam range $180 \mathrm{C}-36^{\circ} \mathrm{C}$, berpengaruh lebih besar menaikkan nilai perubahan warna sampel Sp.B dan Sp.C dibandingkan Sp.A yang relatif lebih stabil.

Analisis kestabilan variabel persen FFA, bilangan peroksida dan warna yang tampak pada ketiga sampel minyak goreng, menunjukkan bahwa sampel Sp.A memiliki tingkat kestabilan lebih baik dibandingkan Sp.B dan Sp.C, dengan demikian dapat disusun urutan mutu dan kualitas ketiga sampel minyak goreng untuk variabel persen FFA, bilangan peroksida dan warna terhadap temperatur penyimpanan setiap kenaikan $2{ }^{\circ} \mathrm{C}$ dengan urutan Sp.A $>$ Sp.B $\geq$ Sp.C. Lebih spesifik analisis setiap variabel menunjukkan bahwa nilai perubahan persen asam lemak bebas (FFA) sampel Sp.A; Sp.B dan Sp.C, ketiganya stabil dalam range temperatur penyimpanan $18{ }^{\circ} \mathrm{C}-36{ }^{\circ} \mathrm{C}$; namun untuk variabel perubahan nilai bilangan peroksida (PV) dan perubahan warna, sampel Sp.A memberi toleransi kestabilan sampai mencapai suhu penyimpanan maksimum $28{ }^{\circ} \mathrm{C}$, sedangkan SP.B dan Sp.C pada suhu lebih rendah maksimum $26{ }^{\circ} \mathrm{C}$.

Mutu dan kualitas minyak goreng kelapa sawit tidak hanya ditentukan dari tiga variabel analisis (FFA; PV dan warna) sebagaimana yang dijadikan variabel uji dalam penelitian ini. Variabel lainnya yang berpengaruh pada kutu dan kualitas minyak goreng, diantaranya: rasa, bau, kandungan kadar air, bilangan asam, kelarutan, titik didih, titik cair, kekeruhan, titik asap, zat pengotor, kebersihan tangki penyimpanan dan faktor lainnya [18], namun untuk perubahan temperatur penyimpanan minyak goreng berpengaruh langsung terhadap persen FFA, bilangan peroksida dan warna.

\section{Kesimpulan}

Berdasarkan data dan analisis yang dilakukan terhadap tiga sampel MGKS, disimpulkan bahwa temperatur penyimpanan berpengaruh terhadap perubahan persen nilai asam lemak bebas (FFA), bilangan peroksida (PV) dan warna ketiga sampel (SP.A; Sp.B Sp.C) minyak goreng kelapa sawit. Mutu dan kualitas sampel Sp.A lebih tinggi dibandingkan sampel Sp.B dan Sp.C. Persen nilai perubahan FFA ketiga sampel stabil pada range $18{ }^{\circ} \mathrm{C}-36{ }^{\circ} \mathrm{C}$ temperatur penyimpanan. Sampel minyak kelapa sawit kode Sp.A lebih stabil dalam mempertahankan nilai perubahan bilangan peroksida (PV) dan warna terhadap perubahan dan kenaikan temperatur penyimpanan dibandingkan Sp.B dan Sp.C. Semua parameter uji yang dilakukan berkaitan mutu dan kualitas MGKS, menunjukkan bahwa sampel Sp.A mengalami rerata kenaikan relatif lebih kecil dibandingkan sampel Sp.B dan Sp.C.

\section{Ucapan terima kasih}

Ucapan terima kasih penulis sampaikan kepada kepala laboratorium dan para laboran pada Laboratorium Biokimia, Jurusan Kimia FMIPA, Universitas Hasanuddin atas peran sertanya dalam menerima dan membantu dalam penyediaan peralatan uji sekaligus kesediaan sebagai konsultan dalam interpretasi data, sehingga penelitian ini dapat dilaksanakan dengan baik dan selesai sesuai target yang telah direncanakan..

\section{Singkatan}

\begin{tabular}{ll}
\hline$M G K S$ & Minyak goreng kelapa sawit \\
$F F A$ & Asam lemak bebas \\
$P V$ & Bilangan peroksida \\
$L R$ & Warna minyak \\
$C P O$ & Crude Palm Oil \\
$\%$ & Persentasi \\
${ }^{\circ} \mathrm{C}$ & Derajat selsius \\
Sp.A & Sampel MGKS tipe A \\
Sp.B & Sampel MGKS tipe B \\
Sp.C & Sampel MGKS tipe C
\end{tabular}

\section{Daftar Pustaka}

[1] Situngkir dan E. Asokawati, "Kinetika perubahan mutu minyak buah merah (Pandanus conoideus) hasil degumming selama penyimpanan," J. Apl. Teknol. Pangan, vol. 7 (4), hal. 156-162, 2018.

[2] M. Gunawan, M. Triatmo, dan A. Rahayu, "Analisis pangan: penentuan angka peroksida dan asam lemak bebas pada minyak kedelai dengan variasi menggoreng," J. KSA, vol. VI (3), hal. 13-16, 2013.

[3] E. C. Hutajulu, N. Nurjazuli, dan N. E. Wahyuningsih, "Hubungan jenis minyak goreng, suhu, dan pH terhadap kadar asam lemak bebas dan minyak goreng pedagang penyetan," J. Media Kesehat. Masy. Indones., vol. 19 (5), hal. 375-378, 2020. 
[4] Y. Kurniati dan W. H. Susanto, "Pengaruh basa NaOH dan kandungan ALB CPO terhadap kualitas minyak kelapa sawit pasca netralisasi," J. Pangan dan Agroindustri, vol. 3 (1), hal. 193-202, 2015.

[5] D. H. Purba, I. Marzuki, M. Dailami, H. A. Saputra, A. M. V. Purba, Biokimia. Medan: Yayasan Kita Menulis, 2021.

[6] M. M. Simarmata, E. Sudarmanto, I. Kato, L. E. Nainggolan, F. Mastutie, Ekonomi Sumber Daya Alam. Medan: Yayasan Kita Menulis, 2021.

[7] K. Kristiandi, S. A. Lusiana, N. A. Q. A'yunin, R. N. Ramdhini, O. S. R. Pasanda. Teknologi Fermentasi. Medan: Yayasan Kita Menulis, 2021.

[8] I. Marzuki, Pengantar Kimia Organik Fisis, 1st ed. Makassar: Tohar Media, 2021.

[9] I. Marzuki, Amirullah, and Fitriana, Kimia dalam Keperawatan. Takalar: Pustaka Al Salam, 2009.

[10] S. Aminah, I. Marzuki, and A. Rasyid, "Analisis kandungan klorin pada beras yang beredar di pasar tradisional Makassar dengan metode argentometri volhard," in Seminar Nasional Pangan, Teknologi, dan Enterpreneurship, 2019, vol. 1, no. 2, pp. 171-175.

[11] Sirlyana, "Pengaruh Waktu Dan Temperatur Penyimpanan Terhadap Kualitas Refined Bleached Deodorized Olein ( RBDOL ) Di PT Nagamas Palmoil Lestari," in Semnas Teknik 2017 Sekolah Tinggi Teknologi Dumai, 2017, vol. 1, no. 1, pp. 75-86.

[12] A. S. Suroso, "Kualitas Minyak Goreng Habis Pakai Ditinjau dari Bilangan Peroksida , Bilangan Asam dan Kadar Air," J. Biomedis dan Teknol., vol. 7, no. 2, pp. 77-98, 2013.

[13] D. A. Anggraini and W. Wijaya, "Analisa Kualitas Crude Palm Oil (CPO) dan Usulan Perbaikan Menggunakan Metode Tree Diagram,” J. Surya Tek., vol. 5, no. 2, pp. 57-62, 2017.

[14] H. Haryono, S. Solihudin, E. Ernawati, and F. Arifiadi, "Biodiesel Dari Minyak Biji Kapuk (Ceiba Pentandra) Terozonasi Melalui Proses Dengan Bantuan Ultrasonik," J. Tek. Kim., vol. 13, no. 2, pp. 61-66, 2019.

[15] M. Busyairi, A. Z. Muttaqin, I. Meicahyanti, and S. Saryadi, "Potensi Minyak Jelantah Sebagai Biodiesel dan Pengaruh Katalis Serta Waktu Reaksi Terhadap Kualitas Biodiesel Melalui Proses Transesterifikasi," J. Serambi Eng., vol. 5, no. 2, pp. 933-940, 2020.

[16] Husnah and Nurlela, "Analisa bilangan peroksida terhadap kualitas minyak goreng sebelum dan sesudah dipakai berulang," J. Tek. Kim. Palembang, vol. 5, no. 1, pp. 65-71, 2020.

[17] R. Luthfian Ramadhan Silalahi, D. Puspita Sari, and I. Atsari Dewi, "Testing of Free Fatty Acid (FFA) and Colour for Controlling the Quality of Cooking Oil Produced by PT. XYZ," Ind. J. Teknol. dan Manaj. Agroindustri, vol. 6, no. 1, pp. 41-50, 2017.

[18] E. Ningsih, S. Suparto, A. Sato, Y. R. Mustikasari, and R. C. Dewi, "Ratio Molar Minyak Sawit Dengan Etanol Konsentrasi Rendah Dalam Pembuatan Biodiesel," J. Tek. Kim., vol. 12, no. 1, pp. $1-4,2017$.

[19] D. R. Pangestuti and S. Rohmawati, "Kandungan Peroksida Minyak Goreng Pada Pedagang Gorengan Di Wilayah Kecamatan Tembalang Kota Semarang," Res. Study, vol. 12, no. 2, pp. 205$211,2018$.

[20] D. R. Pangestuti and S. Rohmawati, "Kandungan Peroksida Minyak Goreng Pada Pedagang Gorengan Di Wilayah Kecamatan Tembalang Kota Semarang," J. Res. Study, vol. V, no. 2, pp. 205$211,2018$.

[21] N. M. S. Sanjiwani, N. M. Suaniti, and N. L. Rustini, "Bilangan peroksida, bilangan asam dan kadar FFA biodiesel dengan penambahan antioksidan dari kulit buah pisang kepok (Musa paradisiaca Linn.)," J. Kim., vol. 9, no. 2, pp. 259-266, 2015.

[22] Sulaiman and R. Randa, "Pengaruh temperatur terhadap efisiensi sterilizer dan kualitas minyak yang dihasilkan,” J. Menara Ilmu, vol. XII, no. 10, pp. 159-169, 2018.

[23] Yeniza and A. P. Asmara, "Penentuan bilangan peroksida minyak RBD (Refined Bleached Deodorized) Olein PT. PHPO dengan metode titrasi Iodometri," J. Amin., vol. 1, no. 2, pp. 79-83, 2019.

[24] Mursalin, Surhaini, and A. Yulia, "Stabilitas Termal Minuman Emulsi dari Pekatan Karoten Minyak Sawit Merah selama Penyimpanan," J. Konversi, vol. 3, no. 1, pp. 37-45, 2014.

[25] N. Dahlia, W. Rahmalia, and T. Usman, "Adsorpsi asam lemak bebas pada crude palm oil menggunakan zeolit terativasi K2CO3," Indo. J. App. Chem, vol. 2, no. 3, pp. 112-120, 2019.

[26] L. Maulinda, N. ZA, and N. Nurbaity, "Hidrolisis Asam Lemak Dari Buah Sawit Sisa Sortiran," J. Teknol. Kim. Unimal, vol. 6, no. 2, pp. 1-15, 2017.

[27] H. Navitania, H. W. Tyanti, and Sukamto, "Minyak Atsiri daun jeruk purut dan sereh dapur pada kalor premium," J. Tek. Kim., vol. 13, no. 2, pp. 44-48, 2019. 